\title{
A Novel Approach for Design and Analysis of Voltage- Controlled DSTATCOM for Power Quality Enhancement
}

\author{
Syed Ruman, Shaik Hameed \\ Quba College of Engg \& Tech., Andhra Pradesh 524320, India \\ email: mhbasha.sk@gmail.com
}

\begin{abstract}
The power fluctuations affect the quality of power supplied by the distributed power system. The Power quality fluctuations of the distributed power system show a serious impact on the robust and sustainable operation of the distributed power system. These power quality fluctuations may be caused due to several reasons like leakage, faults and ageing of the lines. This project proposes a new algorithm to generate reference voltage for a controlled mode distribution static compensator (DSTATCOM) operating in voltage-control mode. The proposed scheme exhibits several advantages compared to traditional voltage-controlled DSTATCOM where the reference voltage is arbitrarily taken as 1.0 p.u. The proposed scheme ensures that unity power factor (UPF) is achieved, while regulating the voltage at the load terminal, during load change, which is not possible in the traditional method. Also, the compensator injects lower currents and, therefore, reduces losses in the feeder and voltage-source inverter. Further, a saving in the rating of DSTATCOM is achieved to increases its capacity to mitigate voltage sag. The statespace model of DSTATCOM is incorporated with the deadbeat predictive controller for fast load voltage regulation during voltage disturbances. With these features, this scheme allows DSTATCOM to tackle power-quality issues by providing power factor correction, harmonic elimination, load balancing, and voltage regulation based on the load requirement. Simulation and experimental results are presented to demonstrate the efficacy of the proposed algorithm.
\end{abstract}

Copyright $(2015$ Institute of Advanced Engineering and Science. All rights reserved.

\section{Introduction}

A Distribution power system suffers from current as well as voltage-related power-quality (PQ) problems, which include poor power factor, distorted source current, and voltage disturbances [1, 2]. A DSTATCOM, connected at the point of common coupling (PCC), has been utilized to mitigate both types of $P Q$ problems [2-12]. When operating in current control mode (CCM), it injects reactive and harmonic components of load currents to make source currents balanced, sinusoidal, and in phase with the PCC voltages [3-7]. In voltage-control mode (VCM) [2], [8-12], the DSTATCOM regulates PCC voltage at a reference value to protect critical loads from voltage disturbances, such as sag, swell, and unbalances. However, the advantages of CCM and VCM cannot be achieved simultaneously with one active filter device, since two modes are independent of each other.

In CCM operation, the DSTATCOM cannot compensate for voltage disturbances. Hence, CCM operation of DSTATCOM is not useful under voltage disturbances, which is a major disadvantage of this mode of operation [13]. Traditionally, in VCM operation, the DSTATCOM regulates the PCC voltage at 1.0 p.u. [2], [8-11]. However, a load works satisfactorily for a permissible voltage range [14]. Hence, it is not necessary to regulate the PCC voltage at 1.0 p.u. While maintaining 1.0-p.u. voltage, DSTATCOM compensates for the voltage drop in feeder. For this, the compensator has to supply an additional reactive current which increases the source currents. This increases losses in the voltage-source inverter (VSI) and feeder. Another important aspect is the rating of the VSI. Due to increased current injection, the VSI is de-rated in steady-state condition. Consequently, its capability to mitigate deep voltage sag decreases. Also, UPF cannot be achieved when the PCC voltage is $1 \mathrm{p} . \mathrm{u}$. In the literature, so far, the operation of DSTATCOM is not reported where the advantages of both modes are achieved based on load requirements while overcoming their demerits.

This paper considers the operation of DSTATCOM in VCM and proposes a control algorithm to obtain the reference load terminal voltage. This algorithm provides the combined advantages of CCM and VCM. The UPF operation at the PCC is achieved at nominal load,

Received November 2, 2014; Revised January 26 2015; Accepted February 15, 2015 
whereas fast voltage regulation is provided during voltage disturbances. Also, the reactive and harmonic component of load current is supplied by the compensator at any time of operation. The deadbeat predictive controller [15-17] is used to generate switching pulses. The control strategy is tested with a three-phase four-wire distribution system. The effectiveness of the proposed algorithm is validated through detailed simulation and experimental results.

\section{Proposed Method}

Power regulation in a Distributed Power System (DPS) is a trival and most important task, which affects the quality of power being supplied from the DPS. The power and voltage levels from the DPS may get disturbed by several factors like line impedance variations due to ageing of the line, increased heat during summer, unnecessary snow and rain fall, corrosion, thunders and storms. But all the applications which rely for their operation on electrical power from the DPS required the power to be supplied at the required rated level. The power quality of the Power Distribution Line Bus (PDLB) may get fluctuated due to a sudden variation in the load impedance, source current levels and input power fluctuations. Whatever it may be the reason for power fluctuation, but the utilities of electrical energy from the DPS cannot continue normal operation, there by demanding regulated rated power quality for lossless and destruction less operation of their internal discrete components. Thus regulations of power levels from the DPS are the most important task and to perform that task, several methods were proposed in the literature. But among them we found that the Distributed STATic COMpensator is best in performance in all aspects compared to all other existing techniques. Since from the operational knowledge of the DSTATCOM we found that, the salient performance features of DSTATCOM are steered by the proper selection of appropriate threshould/reference voltage. The DSTATCOM offers best of its performance if the reference voltage was selected appropriately, otherwise its performance may not be satisfactory. Hence proper selection of reference voltage for the DSTATCOM decides the effectiveness of DSTATCOM in distributed power regulation activities. In this project we are going to design the reference voltage for the DSTATCOM which is designed and implemented using fuzzy logic and being operated in the control mode. The Circuit diagram of a DSTATCOM -compensated distribution system is shown in Figure 1. It uses a three- phase, four-wire, two-level, neutral-point-clamped Voltage Switching Inverter (VSI). This structure allows independent control to each leg of the VSI [7]. Figure 2 shows the single-phase equivalent representation of Figure 1. Variable ' $u$ ' is a switching function, and can be either +1 or -1 depending upon switching state. Filter inductance and resistance are $L_{i}$ and $R_{i}$, respectively. Shunt capacitor $C_{+}^{\prime}$ eliminates high-switching frequency components.

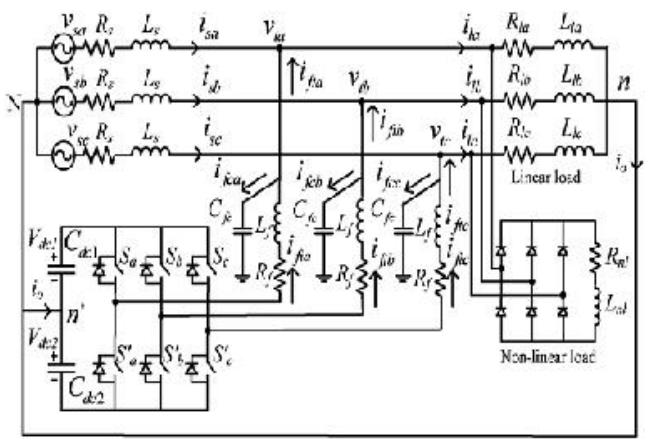

Figure 1. Circuit diagram of the DSTATCOMcompensated distribution system

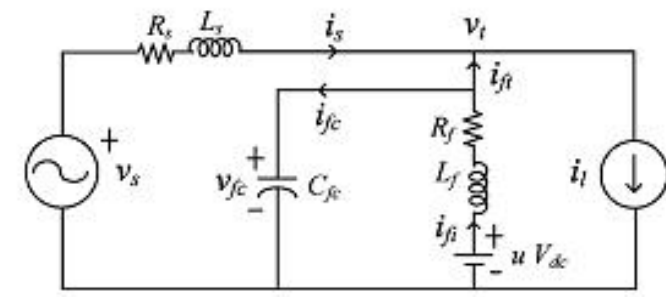

Figure 2. Single-phase equivalent circuit of DSTATCOM

First, discrete modeling of the system is presented to obtain a discrete voltage control law, and it is shown that the PCC voltage can be regulated to the desired value with properly chosen parameters of VSI. Then, a procedure to design VSI parameters is presented. A proportional-integral $(\mathrm{PI})$ controller is used to regulate the dc capacitor voltage at a reference 
value. Based on instantaneous symmetrical component theory and complex Fourier transform, a reference voltage magnitude generation scheme is proposed that provides the advantages of $\mathrm{CCM}$ at nominal load. The overall controller block diagram is shown in Figure 3.

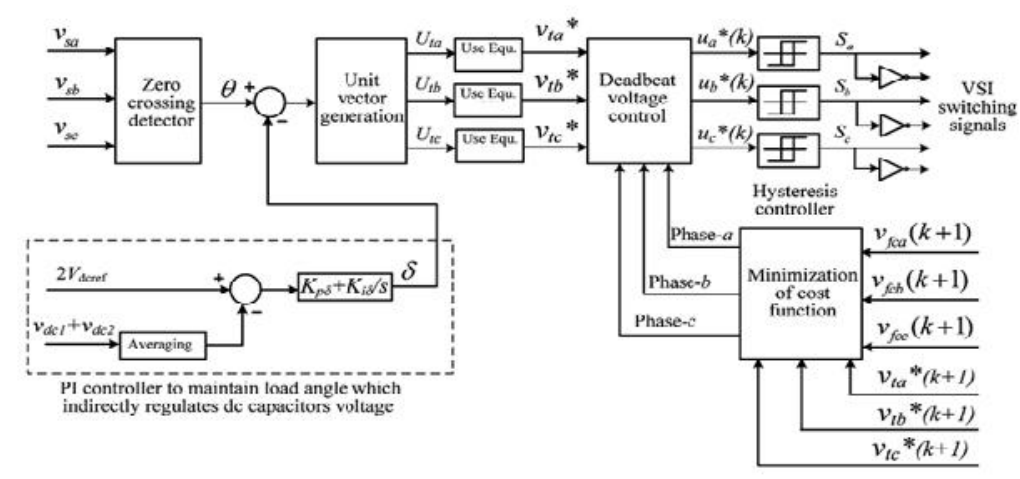

Figure 3. Overall block diagram of the controller to control DSTATCOM in a distribution system

The state-space equations for the circuit shown in Figure 2 are given by:

$$
\dot{x}=A x+B z
$$

Where,

$$
\begin{aligned}
& A=\left[\begin{array}{ccc}
0 & \frac{1}{C_{f c}} & 0 \\
\frac{-1}{L_{f}} & \frac{-R_{f}}{L_{f}} & 0 \\
\frac{-1}{L_{s}} & 0 & \frac{-R_{s}}{L_{s}}
\end{array}\right] \\
& B=\left[\begin{array}{ccc}
0 & -\frac{1}{C_{f c}} & 0 \\
\frac{V_{d c}}{L_{f}} & 0 & 0 \\
0 & 0 & \frac{1}{L_{s}}
\end{array}\right] \\
& \mathrm{X}=\left[\begin{array}{lll}
v_{f i} & i_{f i} & i_{s}
\end{array}\right]^{t}, \mathrm{Z}=\left[\begin{array}{lll}
u & i_{f t} & v_{s}
\end{array}\right]^{t}
\end{aligned}
$$

The general time-domain solution of Equation (1) to compute the state vector $x(t)$ with known initial value $x\left(t_{0}\right)$ is given as follows:

$$
x(t)=e^{A\left(t-t_{0}\right)} x\left(t_{0}\right)+\int_{t_{0}}^{t} e^{A(t-\tau)} B z(\tau) d \tau
$$

The equivalent discrete solution of the continuous state is obtained by replacing $t_{0}=k T_{d}$ and $t=(k+1) T_{d}$ as follows:

$$
x(k+1)=e^{A T_{d}} x(k)+\int_{k T_{d}}^{T_{d}+k T_{d}} e^{A\left(T_{d}+k T_{d}-\tau\right)} B z(\tau) d \tau
$$

Where $k$ and $T_{d}$ represents the $k^{\text {th }}$ sample and sampling period respectively. During the consecutive sampling period, the value of $z(T)$ is held constant, and can be taken as $z(k)$. After simplification and changing the integration variable, Equation (3) can be written as:

$$
x(k+1)=e^{A T_{d}}+\int_{0}^{T_{d}} e^{A \lambda} B d \lambda z(k)
$$

This equation is rewritten as follows: 


$$
x(k+1)=G x(k)+H z(k)
$$

Where $H$ and $G$ are sampled matrices, with the sampling time of $T_{d}$. For Small sampling time, matrices $\mathrm{G}$ and $\mathrm{H}$ are calculated as follows:

$$
\begin{aligned}
& G=\left[\begin{array}{lll}
G_{11} & G_{12} & G_{13} \\
G_{21} & G_{22} & G_{23} \\
G_{31} & G_{32} & G_{33}
\end{array}\right]=e^{A T_{d}} \approx I+A T_{d}+\frac{A^{2} T_{d}^{2}}{2} \\
& H=\left[\begin{array}{lll}
H_{11} & H_{12} & H_{13} \\
H_{21} & H_{22} & H_{23} \\
H_{31} & H_{32} & H_{33}
\end{array}\right]=\int_{0}^{T_{d}} e^{A \lambda} B d \lambda \approx \int_{0}^{T_{d}}(I+A \lambda) B d \lambda .
\end{aligned}
$$

Hence the capacitor voltage is given as:

$$
v_{f c}(k+1)=G_{11} v_{f c}(k)+G_{12} i_{f i}(k)+H_{11} u(k)+H_{12} i_{f t}(k)
$$

As seen from Equation (8), the terminal voltage can be maintained at a reference value depending upon the VSI parameters $V_{d c}, C_{f c}, L_{f}, R_{f}$ and sampling time $T_{d}$. Therefore, VSI parameters must be chosen carefully. Let $v_{t}{ }^{*}$ be the reference load terminal voltage. A cost function $\mathrm{J}$ is chosen as follows.

$$
J=\left[v_{f c}(k+1)-v_{t}{ }^{*}(k+1)\right]^{2}
$$

The cost function is differentiated with respect to $u(k)$ and its minimum is obtained at:

$$
v_{f c}(k+1)=v_{t}^{*}(k+1)
$$

The deadbeat voltage-control law, from (8) and (10), is given as:

$$
u^{*}=\frac{v_{t}^{*}(k+1)-G_{11} v_{f c}(k)-G_{12} i_{f i}(k)-H_{12} i_{f t}(k)}{H_{11}}
$$

The schematic overall block diagram of the proposed controller to control the DSTATCOM in distributed power system is shown in Figure 3, which consists of a zero crossing detector which detects the zero crossing points in three phasor voltage waveforms. Using the result from the zero crossing detector and load angle from the PI controller to maintain dc capacitor voltage, the Unit Vector Generator (UVG) generates three unit threshould vectors for three phasor voltage lines of the DSTATCOM which will be further optimized according to the characteristic equation.

$$
V_{t}^{*}=\sqrt{V^{2}-\left(\left|\bar{I}^{+}\right| X_{s}\right)^{2}-\left|\bar{I}^{+}\right| R_{S}}
$$

The dead beat voltage controller regulates the voltage fluctuations in three Phasor lines in proportion to the feedback control phase sample inputs for three Phasor lines so as to control the cost of power quality regulation process according to the cost function conditionally steered by functional and threshould voltages of three phasors lines of the DSTATCOM. Thus the discrete functional units of DSTATCOM will work.

Reference terminal voltages are generated such that, at nominal load, all advantages of Current Controlled Mode (CCM) operation are achieved while DSTATCOM is operating in Voltage Controlled Mode (VCM). Hence, the DSTATCOM will inject reactive and harmonic components of load current. To achieve this, first the fundamental positive-sequence component of load currents is computed. Then, it is assumed that these currents come from the source and considered as reference source currents at nominal load. With these source currents and for UPF at the PCC, the magnitude of the PCC voltage is calculated. Let threephase load currents. $i_{l a}(t), i_{l b}(t)$ and $i_{l c}(t)$ be represented by the following equations.

$$
i_{l j}(t)=\sum_{n=1}^{m} \sqrt{2} I_{l j n} \sin \left(n w t+\emptyset_{l j n}\right)
$$


Where $j=a, b, c$ represent three phases, ' $n$ ' is the harmonic number, and 'm' is the maximum harmonic order. $\emptyset_{\text {lan }}$ represents the phase angle of the $n^{\text {th }}$ order harmonic with respect to reference in phase-a and is similar to other phases.

\section{Results and Discussion}

The practical implementation of the proposed algorithm for generating the reference voltage of the Distributive Static Compensator (DSTATCOM) operating in the control mode for voltage stability control and analysis of a distributed power system is done by designing the corresponding Simulink models hierarchically to replicate various processing stages involved in designing the DSTATCOM and various processing models using MATLAB/SIMULINK software. The proposed algorithm will includes the design and analysis of various DSTATCOM models as given under.

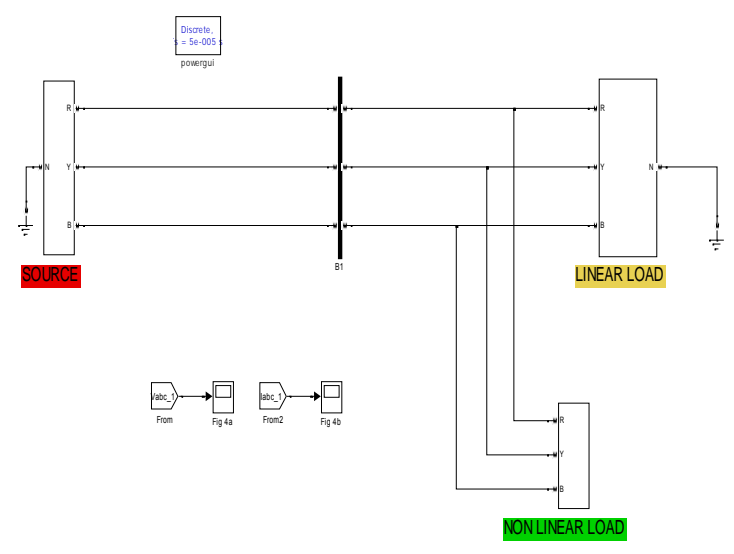

Figure 4. Model before Compensation

The basic DSTATCOM model before compensating the spurious voltage fluctuations in the phasor lines of the Distributed Power System (DPS) is shown in above Figure 4. This model will consists of a distributed Generation based power generation unit which supplies the power to the load units through the three phase lines. The load unit can be either linear load unit or non-linear load unit. The output voltage levels will be displayed on the Oscilloscopes.

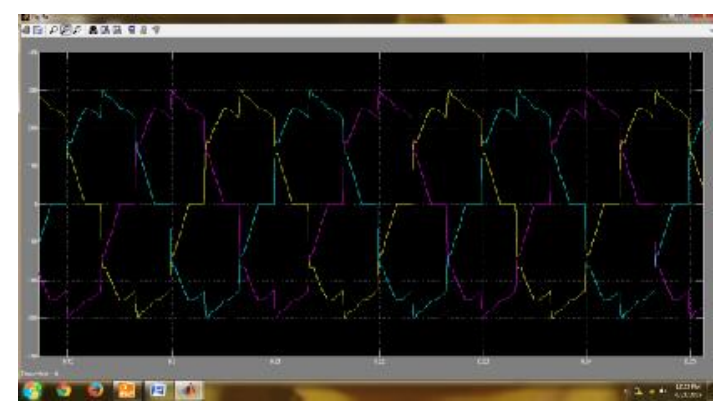

Figure 5. Terminal Voltage waveforms of three phasor lines of the DSTATCOM before compensation

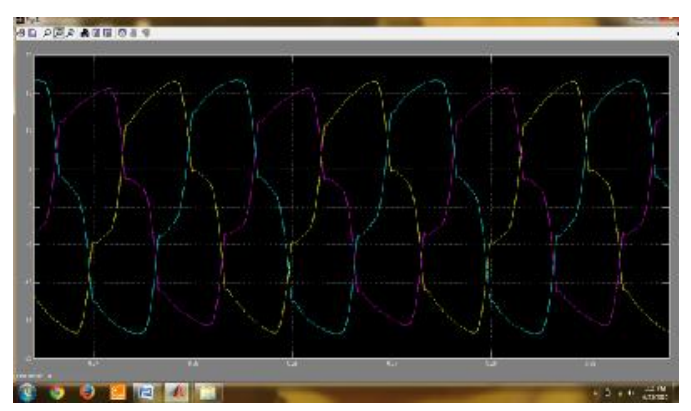

Figure 6. Terminal Current waveforms of the three phasor lines of the DSTATCOM before compensation

The below Figure 7 shows the generalized DSTATCOM model, which employs a similar circuitry as that of the DSTATCOM model without compensation as shown in Figure 4 in 
addition with a compensation circuitry to compensate the voltage fluctuations in the phasor lines of the power distribution system.

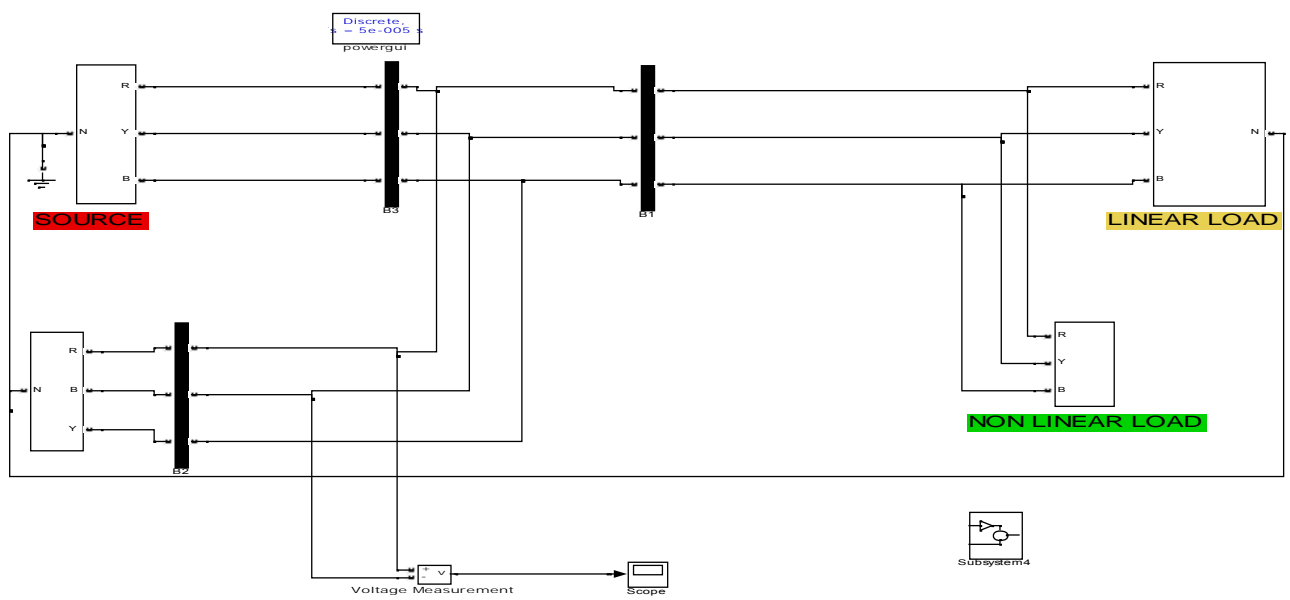

Figure 7. Generalized DSTATCOM Model

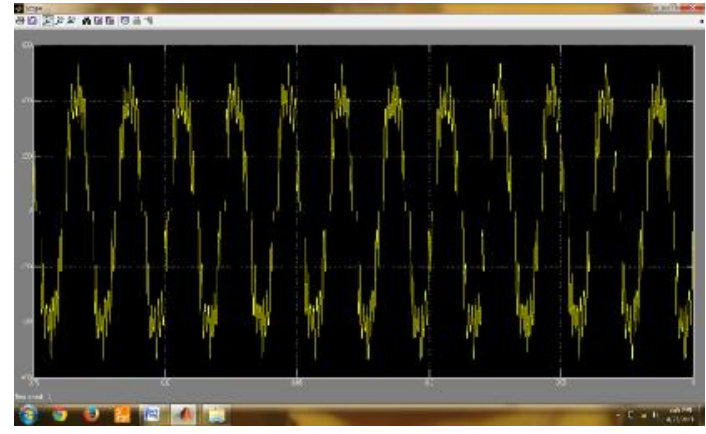

Figure 8. Measured Voltage at the terminals of the generalized DSTATCOM

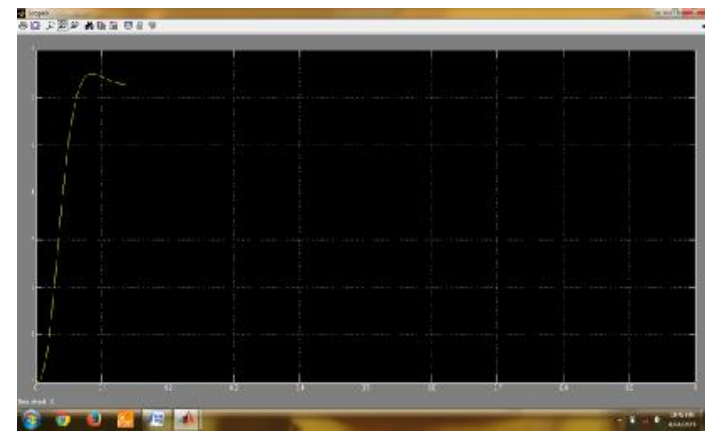

Figure 10. RMS Compensator current of generalized DSTATCOM

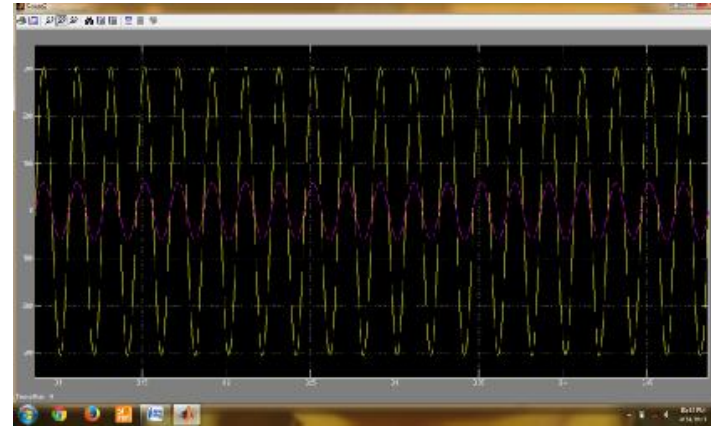

Figure 9. Terminal voltage and currents of a phasor line of generalized DSTATCOM model

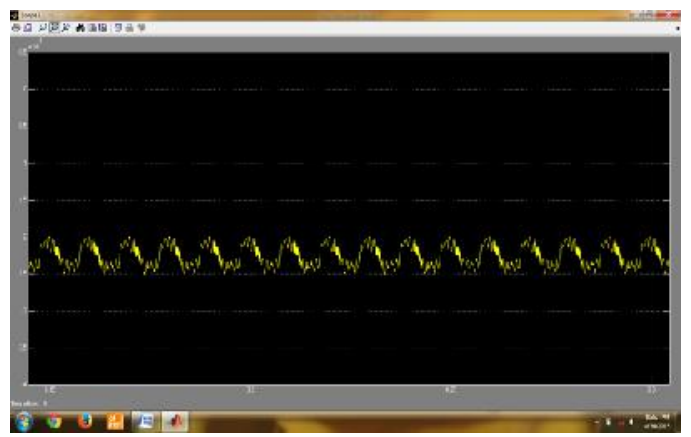

Figure 11. VSC active power waveform of the generalized DSTATCOM 


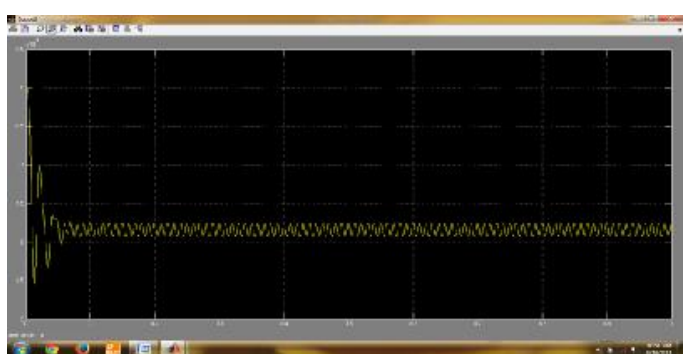

Figure 12. VSC reactive power waveform of the generalized DSTATCOM

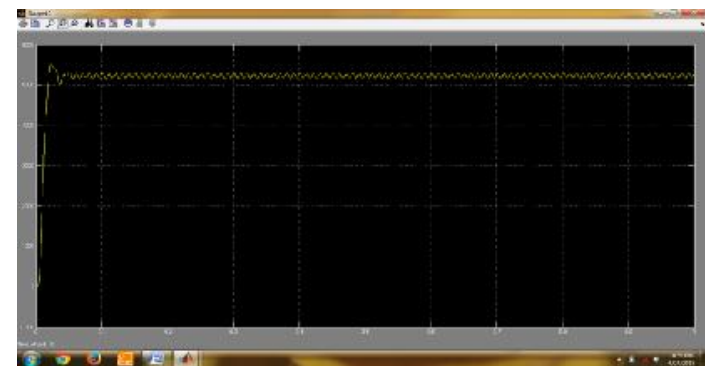

Figure 14. Load reactive power waveforms of the generalized DSTATCOM

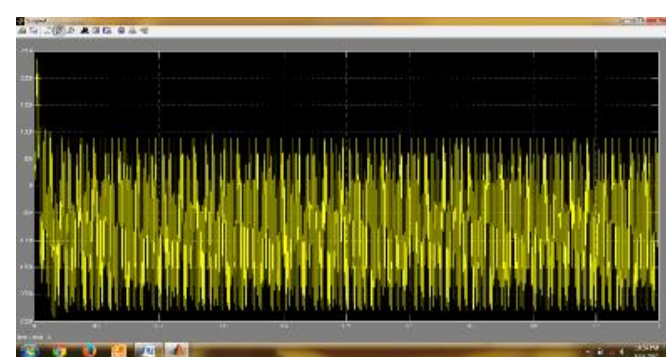

Figure 13. Load active power waveforms of the generalized DSTATCOM

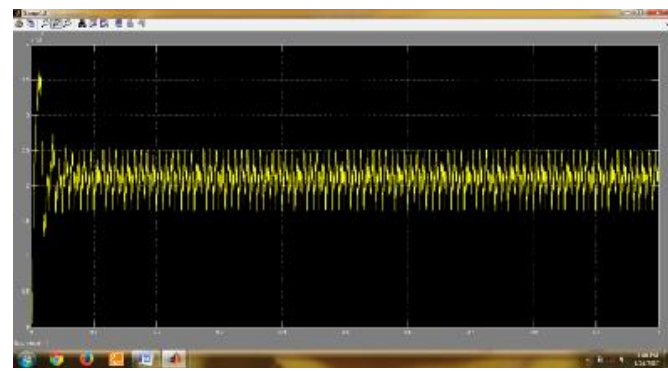

Figure 15. PCC Active power waveforms of the generalized DSTATCOM

Fuzzy logic based implementation is the best technique to explore the reliability and salient performance features of the DSTATCOM. The Robust implementation of the Fuzzy Logic based DSTATCOM model operating in controlled mode is shown in Figure 16.

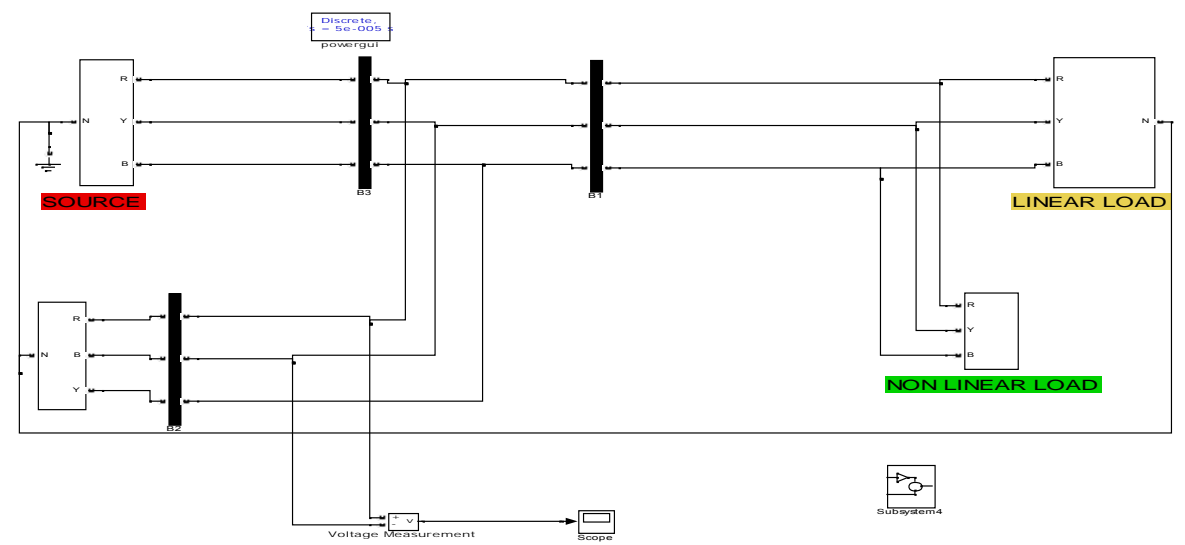

Figure 16. DSTATCOM using Fuzzy logic

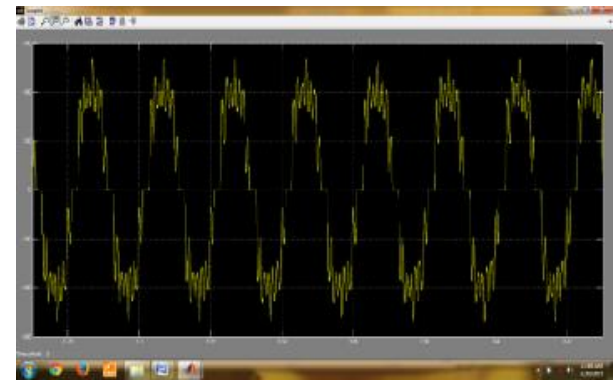

Figure 17. Measured Voltage at the terminals of the DSTATCOM using fuzzy-logic

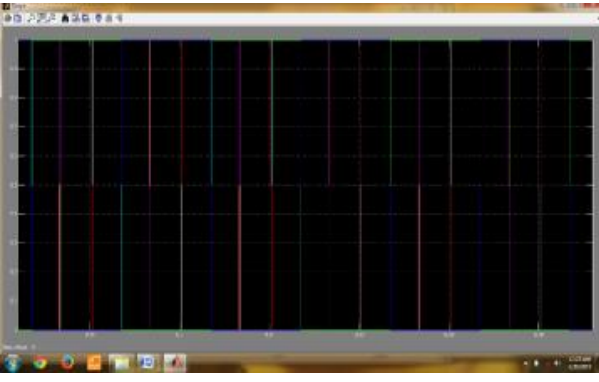

Figure 18. Terminal voltage and currents of the DSTATCOM using the fuzzy-logic 


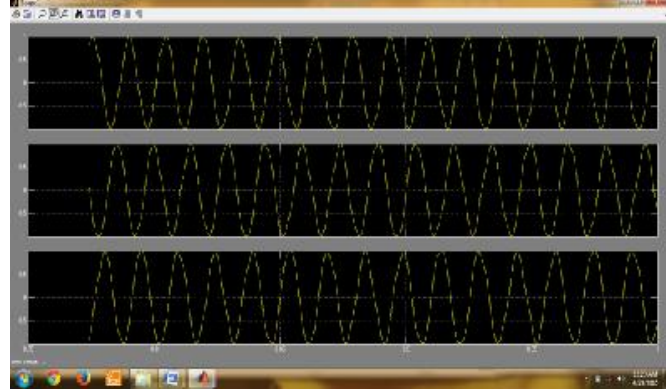

Figure 19. Terminal voltages of the three phasor lines of the DSTATCOM using the Fuzzy-Logic

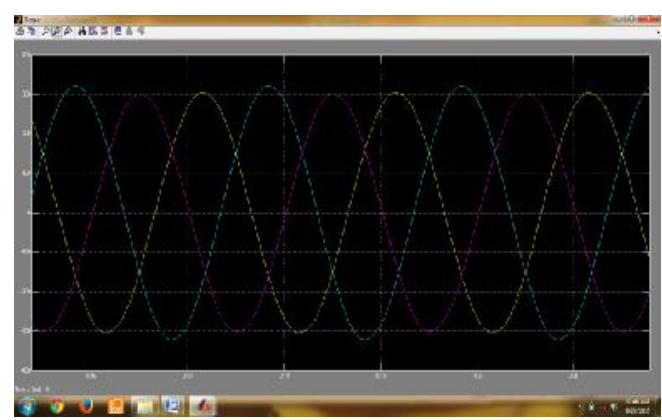

Figure 21. Source voltage waveforms of the three phasor lines of the DSTATCOM using Fuzzy-Logic

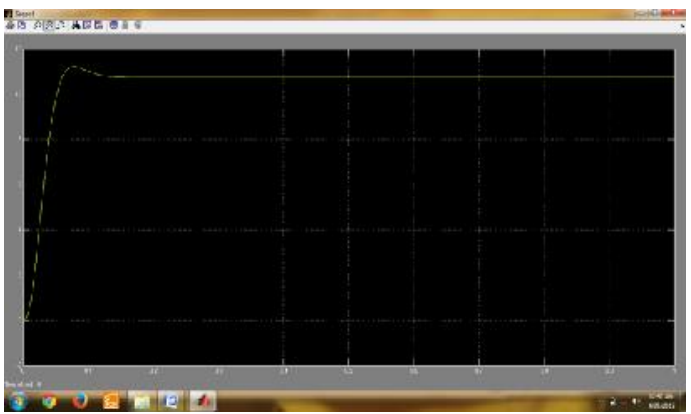

Figure 23. RMS source current waveform of the DSTATCOM using the Fuzzy-Logic

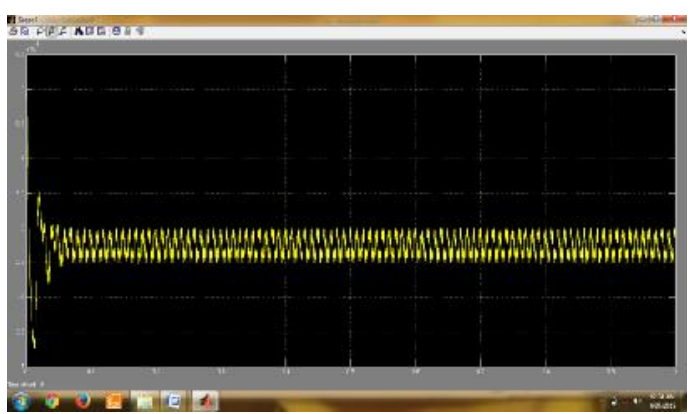

Figure 25. VSC Active power of the DSTATCOM using Fuzzy-Logic

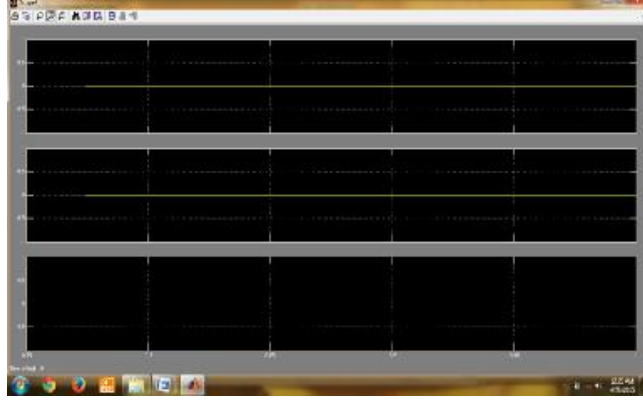

Figure 20. Terminal currents of the DSTATCOM system using the Fuzzy-Logic

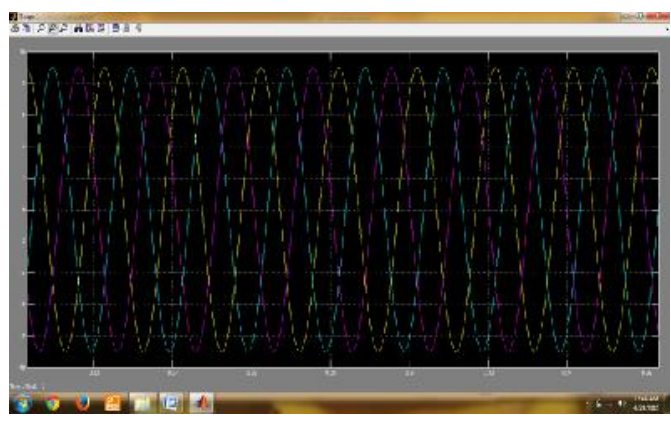

Figure 22. Source current waveforms of the three phasor lines of the DSTATCOM using the Fuzzy-Logic

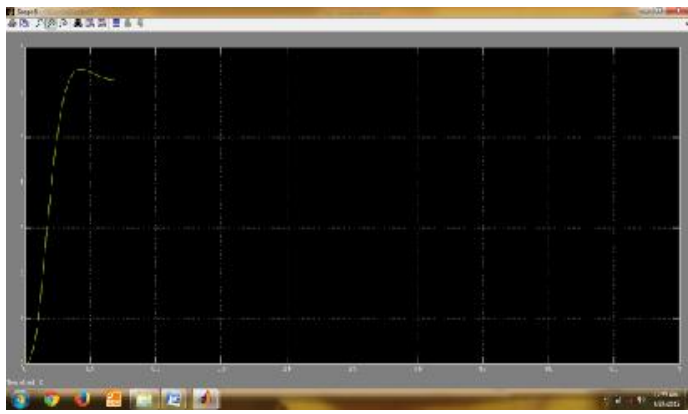

Figure 24. RMS Compensation current of the DSTATCOM using Fuzzy-Logic

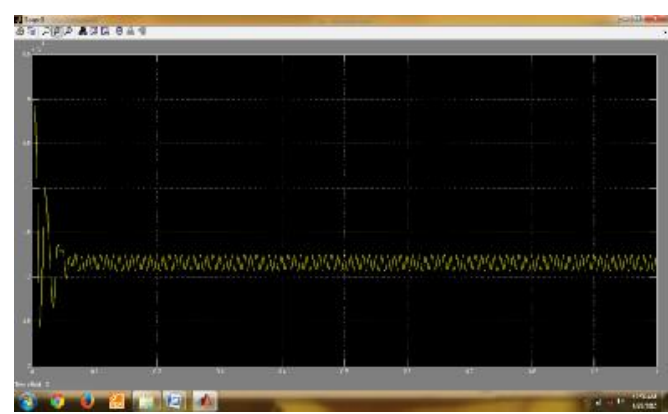

Figure 26. VSC reactive power of the DSTATCOM using the Fuzzy-Logic 


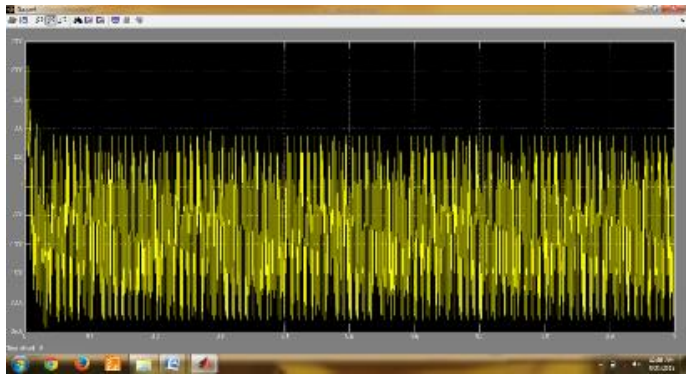

Figure 27. Load active power of the DSTATCOM using the Fuzzy-Logic

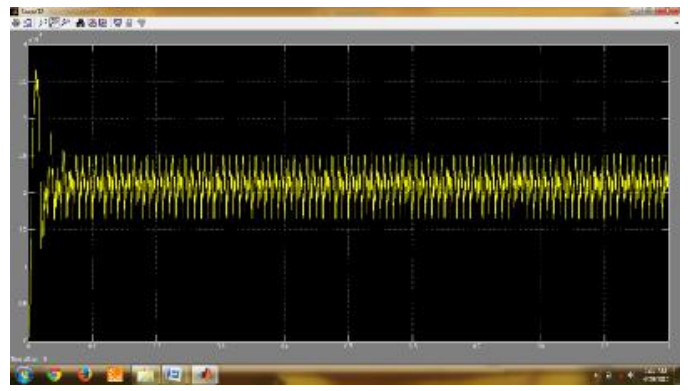

Figure 29. PCC active power of the DSTATCOM using the Fuzzy logic

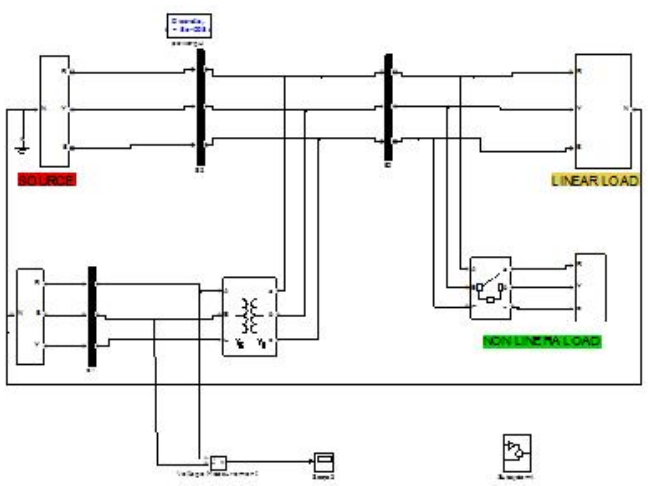

Figure 31. DSTATCOM with lo

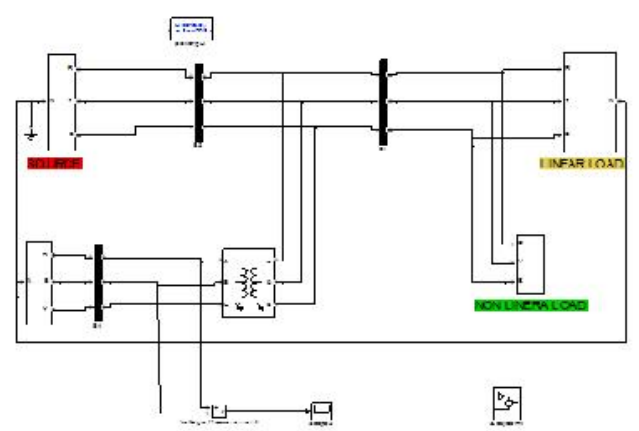

Figure 33. DSTATCOM with SA

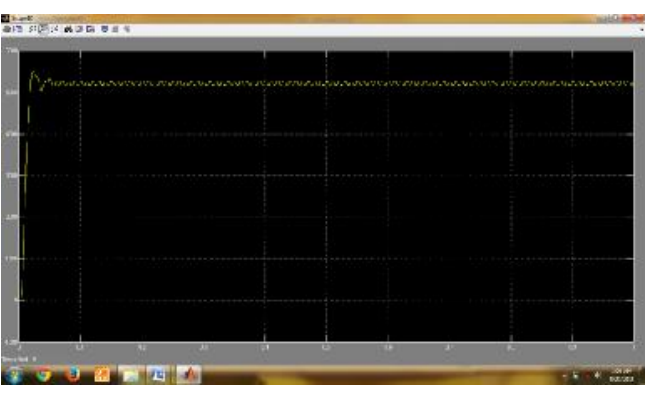

Figure 28. Load reactive power of the DSTATCOM using the Fuzzy-Logic

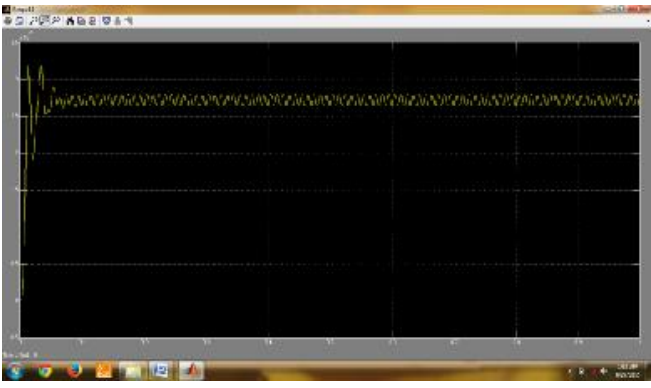

Figure 30. PCC reactive power of the DSTATCOM using the Fuzzy-Logic

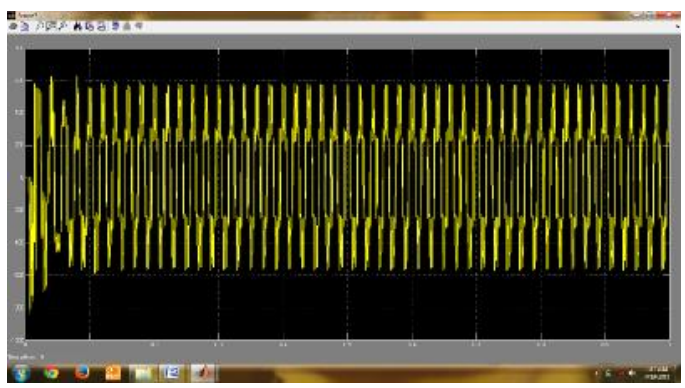

Figure 32. Terminal voltage fluctuations of the three phasor lines of the DSTATCOM with lo

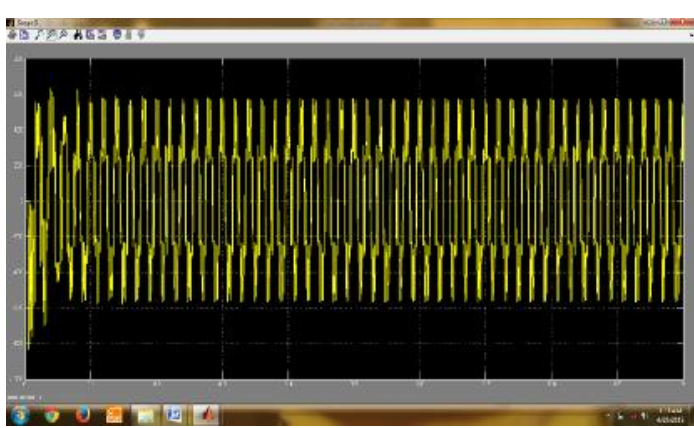

Figure 34. Terminal voltages of the DSTATCOM with line sag modeling using the threshould technique 


\section{Conclusion}

In this paper, we proposed a control algorithm for the generation of reference load voltage for a voltage-controlled DSTATCOM being operated in a control mode. The performance of the proposed scheme is compared with the traditional voltage-controlled DSTATCOM. The proposed method provides the following advantages at nominal load; (a) The compensator injects reactive and harmonic components of load currents, resulting in an UPF; (b) Nearly UPF is maintained for a load change; (c) Fast voltage regulation has been achieved during voltage disturbances; (d) Losses in the VSI; (e) Feeders are reduced considerably, and have higher sag supporting capability with the same VSI rating compared to the traditional scheme. The simulation and experimental results show that the proposed scheme provides DSTATCOM, a capability to improve several PQ problems (related to voltage and current).

\section{Future Scope}

Even though the Distributed STATic COMpensator is proven to be the best in all aspects compared to all other existing techniques. The salient performance features of DSTATCOM are steered by the proper selection of appropriate threshould/reference voltage. The DSTATCOM offers best of its performance if the reference voltage was selected appropriately, otherwise its performance may not be satisfactory. Hence proper selection of reference voltage for the DSTATCOM decides the effectiveness of DSTATCOM in distributed power regulation activities. In this project we designed the reference voltage for the DSTATCOM which is designed and implemented using fuzzy logic and being operated in the control mode. There is a huge scope to extend the work further to improve the operational effectiveness of the DSTATCOM operating in the control mode by just optimizing the threshold/reference voltage designed for DSTATCOM.Reference voltage optimization enables the control voltage design to be appropriate which enables the DSTATCOM to deliver best of its performance.

\section{References:}

[1] M Bollen. Understanding Power Quality Problems. IEEE. Piscataway, NJ, USA. 2000; 1: 1-35.

[2] H Fujita, H Akagi. Voltage-regulation performance of a shunt active filter intended for installation on a power distribution system. IEEE Trans. Power Electron. 2007; 22(3): 1046-1053.

[3] A Ghosh, G Ledwich. Load compensating DSTATCOM in weak ac systems. IEEE Trans Power Del. 2003; 18(4): 1302-1309.

[4] A Elnady, M Salama. Unified approach for mitigating voltage sag and voltageflicker using the DSTATCOM. IEEE Trans Power Del. 2006; 20(2): 992-1000.

[5] S Rahmani, A Hamadi, K Al-Haddad. A Lyapunov-function based control for a three-phase shunt hybrid activefilter. IEEE Trans Ind Electron. 2012; 59(3): 1418-1429.

[6] MK Mishra, K Karthikeyan. A fast-acting dc-link voltage controller for three-phase DSTATCOM to compensate ac and dc loads. IEEE Trans Power Del. 2009; 24(4): 2291-2299.

[7] MK Mishra, A Ghosh, A Joshi, HM Suryawanshi. A novel method of load compensation under unbalanced and distorted voltages. IEEE Trans Power Del. 2007; 22(1): 288-295.

[8] MK Mishra, A Ghosh, A Joshi. Operation of a DSTATCOM in voltage control mode. IEEE Trans Power Del. 2003; 18(1): 258-264.

[9] A Jain, K Joshi, A Behal, N Mohan. Voltage regulation with STATCOMs: Modeling, control and results. IEEE Trans Power Del. 2006; 21(2): 726-735.

[10] R Gupta, A Ghosh, A Joshi. Switching characterization of cascaded multilevel-inverter-controlled systems. IEEE Trans Ind Electron. 2008; 55(3): 1047-1058.

[11] P Mitra, G Venayagamoorthy. An adaptive control strategy for DSTATCOM applications in an electric ship power systems. IEEE Trans Power Electron. 2010; 25(1): 95-104.

[12] A Yazdani, M Crow, J Guo. An improved nonlinear STATCOM control for electric arc furnace voltage flicker mitigation. IEEE Trans Power Del. 2009; 24(4): 2284-2290.

[13] SH Ko, S Lee, H Dehbonei, C Nayar. Application of voltage and current-controlled voltage source inverters for distributed generation systems. IEEE Trans Energy Convers. 2006; 21(3): 782-792.

[14] M Moradlou, H Karshenas. Design strategy for optimum rating selection of interline DVR. IEEE Trans Power Del. 2011; 26(1): 242-249.

[15] J Rodriguez, J Pontt, CA Silva, P Correa, P Lezana, P Cortes, U Amman. Predictive current control of a voltage source inverters. IEEE Trans Ind Electron. 2007; 54(1): 495-503.

[16] J Barros, J Silva. Multilevel optimal predictive dynamic voltage restorer. IEEE Trans Ind Electron. 2010; 57(8): 2747-2760. 
[17] O Kukrer. Discrete-time current control of voltage-fed three-phase PWM inverters. IEEE Trans Power Electron. 1996; 11(2): 260-269.

[18] I Nagrath, M Gopal. Control Systems Engineering. NewYork, USA: Halsted. 1982: 518-519.

[19] B Singh, P Jayaprakash, T Somayajulu, D Kothari. Reduced rating VSC with a zig-zag transformer for current compensation in a three-phase four-wire distribution system. IEEE Trans Power Del. 2009; 24(1): 249-259. 